\title{
Cryopreservation of Coffea arabica L. Zygotic Embryos by Vitrification
}

\author{
Rodrigo Therezan de FREITAS ${ }^{1 *}$, Renato PAIVA ${ }^{1}$, Thais Silva SALES ${ }^{1}$, \\ Diogo Pedrosa Corrêa da SILVA ${ }^{1}$, Michele Valquíria dos REIS ${ }^{1}$, \\ Ana Cristina de SOUZA ${ }^{1}$, Sttela Dellyzete Veiga Franco da ROSA ${ }^{2}$
}

\author{
${ }^{1}$ Universidade Federal de Lavras (UFLA), Departamento de Biologia, Setor de Fisiologia Vegetal, Campus Universitário, 372000-000, Lavras \\ MG,Brazil; rodrigotfreitas@hotmail.com ("correspondingauthor); renpaiva@ufla.br; thaisinha-sales@hotmail.com; \\ pedrosacorrea@hotmail.com;mvreis@yahoo.com.br;acstina@hotmail.com \\ ${ }^{2}$ EMBRAPA, AvenidaW3 Norte (Final), Parque Estação Biológica, 70770-901 Brasilia DF, Brazil; sttela.rosa@embrapa.br
}

\begin{abstract}
As a consequence of the difficulty in conventional coffee seed storage, biotechnological alternatives such as cryopreservation have been investigated. The objective of this study was to develop a protocol for the cryopreservation of Coffea arabica L. (cv. 'Catuaí Vermelho' - IAC 144) zygotic embryos by vitrification. For the cryopreservation study, the embryos were immersed in Plant Vitrification Solution 2 at different times (0, 10, 25, 50, 100, and $250 \mathrm{~min})$ and two temperatures $\left(0\right.$ and $\left.25^{\circ} \mathrm{C}\right)$. Subsequently, the best thawing time was determined in a water bath $(1,3,5$ minutes or directly in Recovery Solution). An anatomical study was conducted on non-stored and stored embryos, with or without the use of Plant Vitrification Solution 2. The immersion in cryoprotectant solution for $100 \mathrm{~min}$ at $0{ }^{\circ} \mathrm{C}$ allows embryo cryopreservation. Embryos can be directly thawed in Recovery Solution after storage in liquid nitrogen. It was observed that Plant Vitrification Solution 2 reduced internal water content in the cells, allowing subsequent embryo growth resumption.
\end{abstract}

Keywords: ex situ conservation, histology, liquid nitrogen, PVS2, thawing, TTC test

\section{Introduction}

Brazil is the largest producer and exporter of coffee, which is the fifth most exported agricultural product (Conab, 2016). Due to the economic and social importance of coffee to Brazil, it is necessary that measures be taken for the conservation of its genetic resources.

Genetic diversity is necessary in breeding programs to provide resistance to pests and diseases, besides tolerance to environmental stress, and also to improve beverage quality and increase yield (Nass et al., 2008; Dulloo et al., 2009). However, coffee seeds have limitations on their conservation, since they are classified as intermediate, sensitive to desiccation and low temperatures, preventing conventional seed bank storage (Araujo et al., 2008; Simoes-Costa et al., 2009).

As a result of the difficulty in coffee seed storage, the main conservation form of coffee genetic diversity has been carried out ex situ by planting seedlings directly in the field. However, this conservation form requires large areas, a high maintenance cost and there are many risks that can lead to the loss of genetic diversity (Valdés, 2012). Therefore, biotechnological alternatives such as cryopreservation have been investigated for coffee germplasm conservation (Dussert et al., 1997; SantanaBuzzy et al., 2007).

Among the cryopreservation techniques, vitrification is a method in which biological material is exposed to high concentrations of cryoprotectant solutions. These solutions convert the internal water content to an amorphous state, thus allowing the biological material to be rapidly reach liquid nitrogen temperature (Sakai and Engelmann, 2007).

Cryopreservation has been reported as a viable conservation form for Coffea spp. (Santana-Buzzy et al., 2007), although most studies have been conducted with seeds, whereas it is known that seeds have a rapid loss of viability and differ in their tolerance to dehydration (Dussert et al., 1998). Therefore, the seed batch used must have a high initial quality, for a successful cryopreservation (Dussert and Engelmann, 2006).

Recently, we developed a protocol through which coffee zygotic embryos can be successfully cryopreserved using physical dehydration in silica gel, followed by osmotic rehydration after thawing (Pinto et al., 2016). However, up to the moment, there is no report on coffee zygotic embryos cryopreservation by vitrification. 
446

Zygotic embryos may be an alternative as an explant for cryopreservation by vitrification, since embryo-forming tissues facilitate the penetration of cryoprotectant solutions and their dehydration, as they are more impermeable than the seed endosperm. Embryos also provide the genetic variability necessary for breeding programs, thus as seed (Santana-Buzzy et al., 2007), and a more uniform and fast germination in relation to whole seeds (Bojórquez-Quintal et al., 2011).

Coffea arabica $\mathrm{L}$. is the most important species in the genus Coffea, accounting for more than $76 \%$ of Brazil's total coffee production (Conab, 2016). Among the Coffea arabica L. species, the variety Catuai is one of the most widespread in Brazil and has been widely used due to its beverage quality (Silva et al., 2016).

In this context, the objective of this study was to develop a protocol for the cryopreservation of Coffea arabica L. cv. ‘Catuaí Vermelho' (IAC 144) zygotic embryos through vitrification.

\section{Materials and Methods}

\section{Plantmaterial}

Coffea arabica L. (cv. 'Catuaí Vermelho' - IAC 144) seeds were obtained on the experimental farm of Empresa de Pesquisa Agropecuária de Minas Gerais (EPAMIG), located in Três Pontas - MG, Brazil. For disinfection, seed endocarp (parchment) was manually removed and, following the methodology used by Dela Cruz et al. (1992) with minor modifications, the seeds were immersed in $1.6 \%$ formaldehyde for 30 minutes, followed by $0.5 \%$ boric acid for 72 hours, both under stirring at $150 \mathrm{rpm}$ and $25^{\circ} \mathrm{C} \pm 2{ }^{\circ} \mathrm{C}$. In a flow chamber, the seeds were washed three times in distilled and autoclaved water for later embryos removal. Initially, the seeds had $10 \%$ water content and, after disinfection, it increased to 55\%, which allowed embryo excision.

Determination of time and exposure temperature to Plant Vitrification Solution 2

Cryopreservation was performed by vitrification, with protocol adjustments described by Sakai and Engelmann (2007).

The excised embryos were exposed to Loading Solution (LS) [2 M glycerol $+0.4 \mathrm{M}$ sucrose in liquid MS] (Matsumoto et al., 1994) for 20 minutes at room temperature and immersed in Plant Vitrification Solution 2 (PVS2) [30\% glycerol + 15\% ethylene glycol $+15 \%$ DMSO + 0.4 M sucrose in liquid MS] (Sakai et al., 1990) at $0^{\circ} \mathrm{C}$ or room temperature (approximately $\left.25^{\circ} \mathrm{C} \pm 2{ }^{\circ} \mathrm{C}\right)$, at different time intervals $(0,10,25,50,100$ and 250 minutes) in a factorial scheme with 6 immersion times $\times 2$ PVS2 immersion temperatures. After each time interval, the embryos from each treatment were placed into $2-\mathrm{mL}$ cryovials containing $0.5 \mathrm{~mL}$ PVS2 and immersed in liquid nitrogen (LN) $\left(-196^{\circ} \mathrm{C}\right)$ for 60 minutes. After storage, the embryos were thawed in Recovery Solution (RS) [1.2 M sucrose dissolved in liquid MS] (Sakai et al., 1990) for 15 minutes at room temperature. Embryos not immersed in LN (control) were also directly immersed in RS. After the immersion period in RS, all treatments and their controls were inoculated in regeneration medium for in vitro growth.

\section{Determination of thawing time}

For thawing time, the embryos were stored in $\mathrm{LN}$ using the best time and exposure temperature in PVS2 found in the previous experiment. Subsequently, they were thawed in a water bath at $40{ }^{\circ} \mathrm{C} \pm 2{ }^{\circ} \mathrm{C}$ for different times $(0,1,3$ and 5 minutes), and then immersed for 15 minutes in RS at room temperature. The control (time zero) was directly thawed in RS for 15 minutes at room temperature. Next, the embryos were inoculated in recovery medium for in vitro growth.

\section{Viability in tetrazolium salt}

Fifteen embryos in each treatment were washed in distilled water immediately after thawing, and soaked in a $0.5 \%$ solution of 2,3,5-Triphenyltetrazolium chloride (TTC), standing in the absence of light in a BOD incubator at $30^{\circ} \mathrm{C}$ for 2 hours. Subsequently, the embryos were washed in running water, observed individually and classified as viable or not viable, according to the intensity and location of the visible staining observed, using the criteria described by Clemente et al. (2012).

The results were expressed as percentage of viable embryos (\%) after thawing.

\section{In vitro growth}

After thawing, the embryos were inoculated in MS recovery medium supplemented with $30 \mathrm{gL}^{-1}$ sucrose, solidified with $2.5 \mathrm{~g} \mathrm{~L}^{-1}$ Phytagel; $\mathrm{pH}$ was adjusted to 5.8 before autoclaving, which was performed at $121^{\circ} \mathrm{C}$ for 20 minutes.

Zygotic embryos remained in a growth room in the dark for three days at $25 \pm 2{ }^{\circ} \mathrm{C}$ to prevent possible oxidations. After this period, they were transferred to a 16 -hour photoperiod, with photon irradiance of $36 \mu \mathrm{mol} \mathrm{m}^{-2} \mathrm{~s}^{-1}$ at $25 \pm 2^{\circ} \mathrm{C}$.

After 30 days, the percentage of germination and normal seedlings was evaluated. The embryo that had a visible growth in the shoot and hypocotyl-radicle axis was considered germinated, and seedlings were considered normal when both shoot and cotyledons, as well as the hypocotyl-radicle axis, had no damage or abnormalities throughout growth, showing similarity to the control.

\section{Histological analysis}

Light microscopy was performed on histological slides of embryos which were previously stored in LN without PVS2 pretreatment, embryos stored in LN using the best treatment (time and temperature) in PVS2, and embryos just excised from seeds (control). The embryos from each treatment descrived above were fixed and stored in ethanol $70 \%$ after thawing in RS. Dehydration was performed in an ascending ethanol series (70\%, 80\%, 90\% and 100\%), remaining at each concentration for 1 hour. After dehydration, infiltration with plastic resin hydroxyethyl methacrylate (Leica Historesin; Heraeus Kulzer, Hanau, Germany) was carried out according to the manufacturer's instructions.

Transverse sections with $5 \mu \mathrm{m}$ thickness were cut with a rotary microtome (Leica RM 2045), and subsequently stained in $0.1 \%$ toluidine blue (Sridharan and Shankar, 2012). Sections were observed at $\times 20$ and $\times 40$ magnifications and images were digitally captured using a Leica DMLB microscope with a video camera coupled to a computer running IM50 software (Leica Microsystems). 


\section{Statistical analysis}

A completely randomized design in 5 replicates with 3 explants was used. The results, expressed in percentage, were calculated using the formula $\left[\mathrm{G}(\%)=\left(\sum \mathrm{n}_{\mathrm{i}}\right) \cdot \mathrm{N}^{-1} \cdot 100\right.$, where: $\mathrm{n}_{\mathrm{i}}$ = number of germinated embryos, $\mathrm{N}=$ number of embryos placed to germinate], and were arcsin-transformed $(\mathrm{x} / 100) 0.5$.

Data were submitted to analysis of variance (ANOVA) using the statistical software SISVAR (Ferreira, 2014) and means were analyzed by the Scott-Knott test at $5 \%$ probability.

\section{Results and Discussion}

Determination of time and exposure temperature to Plant Vitrification Solution 2

At $0{ }^{\circ} \mathrm{C}$, embryos not stored in $\mathrm{LN}$ that were treated with PVS2 showed $100 \%$ germination and $100 \%$ formation of normal seedlings, regardless of their immersion time in the cryoprotectant solution (Figs. 1A, 1B and 1C).

On the other hand, at $25^{\circ} \mathrm{C}$, germination and the formation of normal seedlings occurred only at the initial exposure times to PVS2 (10 min and $25 \mathrm{~min}$ ) (Figs. $1 \mathrm{~B}$ and
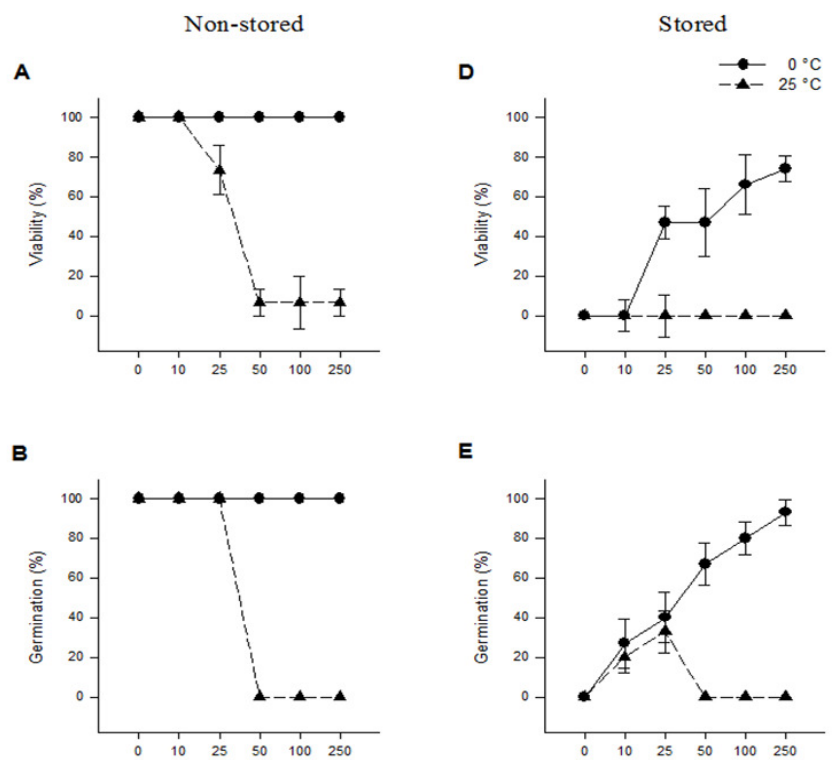

c

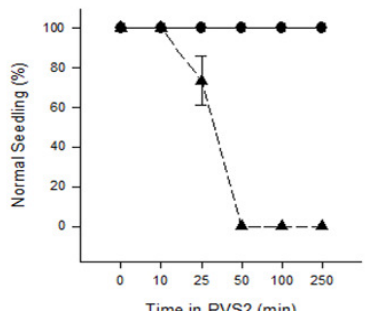

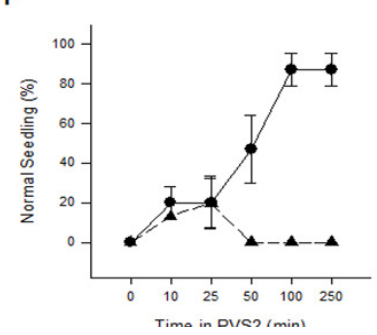

1C). In treatments in which the embryos remained in PVS2 for longer than 25 minutes, germination or normal seedlings did not occur, and the embryos showed reduced viability in tetrazolium salt (Fig. 1A).

The low viability in tetrazolium salt and the nongermination of embryos treated with PVS2 at immersion times higher than 25 minutes at $25{ }^{\circ} \mathrm{C}$ show that, under these conditions, the cryoprotectant was toxic to embryos. Similar results were obtained by (Lambardi et al., 2000) in the vitrification of Populus alba L. apical buds treated with PVS2 solution for a time period of over 20 minutes at $25^{\circ} \mathrm{C}$ or above 60 minutes at $0{ }^{\circ} \mathrm{C}$, which showed clear damage symptoms caused by toxicity or osmotic stress, such as bleaching or lack of growth recovery. It was also observed for Cocos nucifera L., that the prolonged embryos exposure to plant vitrification solution resulted in a lower viability (Sajini et al., 2011).

PVS2 may have a high chemical toxicity due to the presence of the permeable cryoprotectants DMSO and ethylene glycol in its constitution. This toxicity can be enhanced when it is applied at room temperature (Kulus and Zalewska, 2014). At higher temperatures, the vitrifying solution (PVS2) has a higher penetration capacity in tissues (Yi et al., 2012). Conversely, at lower temperatures, solution mobility is reduced, decreasing the penetration rate through the plasma membrane, preventing the toxic effect and excessive explant dehydration (Kim et al., 2009).

Despite the toxic and osmotic effects that PVS2 constituents may present in certain conditions, PVS2 solution

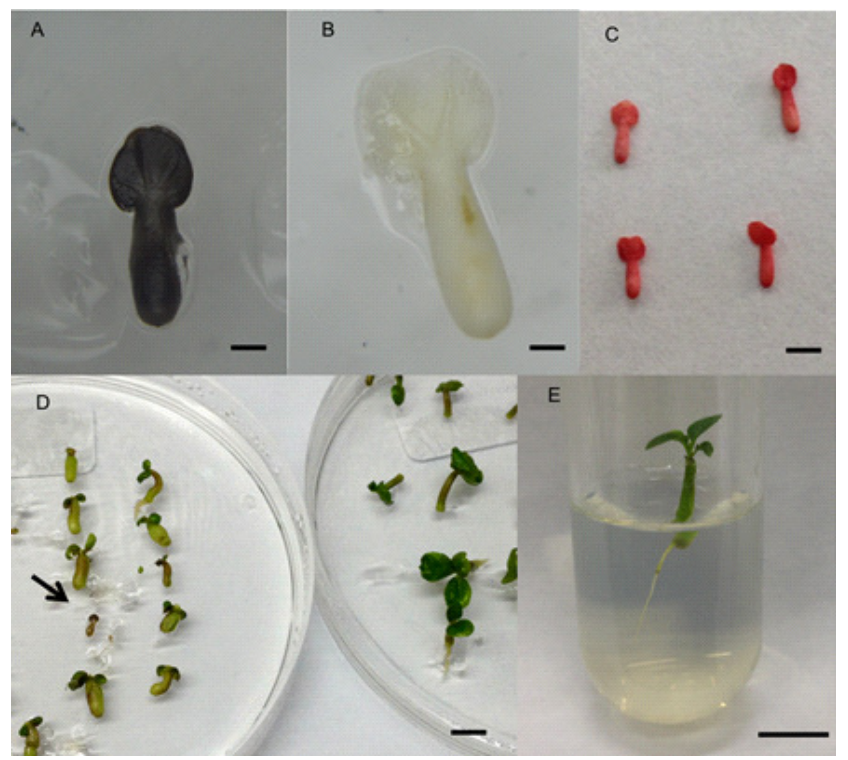

Fig. 2. Zygotic embryo with 30 days after thawing which was previously stored in LN without PVS2, bar: $1 \mathrm{~mm}$. (A). Zygotic embryo with 2 days after thawing which was previously treated with $100 \mathrm{~min}$ PVS2 at $0{ }^{\circ} \mathrm{C}$ and then stored in LN, bar: $0.7 \mathrm{~mm}(\mathrm{~B})$. Visual aspect of viable embryos stained with tetrazolium solution, bar: $3 \mathrm{~mm}$ (C). Visual aspect of stored (left) and non-stored (right) embryos after 30 days of culture (the arrow indicates non-surviving embryos), bar: 0.5 $\mathrm{cm}$ (D). Seedlings grown in vitro derived from the embryo cryopreserved after 60 days, bar: $1 \mathrm{~cm}(\mathrm{E})$

Fig. 1. Percentage of viability, germination and normal seedlings obtained from zygotic embryos subjected to different times $(0,10,25,50,100$ and $250 \mathrm{~min})$ and immersion temperatures $\left(0\right.$ and $25^{\circ} \mathrm{C}$ ) in PVS2 cryoprotective solution, after storage or not in LN after 30 days in culture. The bars represent the mean standard error, according to the ScottKnott test at 5\% probability 
is required for vitrification and later explant cryopreservation. A proof of this is that embryos that were not immersed in PVS2 (time 0), when subjected to storage in $\mathrm{LN}$ and subsequently thawed, showed no viability in tetrazolium test and did not germinate (Figs. 1D, 1E and 1F); oxidation was also observed (Fig. 2A), unlike LN-stored embryos after the treatment with PVS2 (Fig. 2B). The non-survival of embryos without immersion in PVS2 (time zero) was expected, since the water content was very high in these embryos, which led to the formation of large ice crystals bursting the cell during freezing and thawing (Tao and $\mathrm{Li}, 1986$ ).

Unlike the embryos not treated with PVS2 (time 0), which did not germinate after storing in liquid nitrogen, the embryos immersed in the cryoprotectant solution at $0{ }^{\circ} \mathrm{C}$ after thawing showed viability in tetrazolium salt (Figs. $1 \mathrm{D}$ and 2C), germination and formation of normal seedlings during in vitro growth. It was observed that, with increasing immersion times in PVS2 at $0{ }^{\circ} \mathrm{C}$, there was an increase in viability, germination and formation of normal seedlings (Figs. 1D, 1E and 1F).

According to Sakai and Engelmann (2007), the success of cryopreservation via vitrification is in the optimization of time and exposure temperature to PVS2 for a rapid explant vitrification during storage in $\mathrm{LN}$. The treatment with PVS2 leads to explant dehydration, due to water transfer, since the mass of water lost from the cell corresponds to the input mass of the cryoprotectant solution. The PVS2 solution also leads to in cryoprotection, reducing the mobility of water molecules, allowing vitrification to occur during storage in LN (Volk and Walters, 2006).

After storage in LN, the embryos which were immersed in PVS2 at $25^{\circ} \mathrm{C}$ for time periods exceeding $25 \mathrm{~min}$, did not survive, as expected. Even under non-storage conditions, PVS2 had already been toxic to the embryos, as described above. On the other hand, at times lower than 50 minutes (10 and 25 minutes) at $25{ }^{\circ} \mathrm{C}$, the embryos showed only $20 \%$ and $33 \%$ germination, and $13 \%$ and $27 \%$ formation of normal seedlings, respectively, with almost no viability in the tetrazolium test (Figs. 1D, 1E and 1F).

The highest percentage of viability $(73 \%)$ and germination (93\%) was observed at the highest immersion time (250 minutes) in PVS2 at $0{ }^{\circ} \mathrm{C}$. However, it was not statistically different from 50 and 100 minutes under the same conditions (Figs. 1D and 1E), and embryo treatment for 100 and 250 minutes in this solution yielded $87 \%$ formation of normal seedlings at both times (Fig. 1F). Thus, there was no statistical difference between 100 and 250 minutes in all tested parameters. Therefore, 100 minutes in PVS2 was used for subsequent experiments.

Regarding embryo viability in the tetrazolium test, it was observed that, despite the variation within treatments, it was possible to obtain a good survival indication (Figs. 1A and 1D), since the results obtained for viability showed the same trend as those obtained for germination. However, precautions must be taken to interpret the results of this technique since, after recovery from $\mathrm{LN}$, viable plant tissues can still die during regeneration, as well as explants that contain weakened cells, which can be interpreted as non-viable and can regenerate (Verleysen et al., 2004). Due to this fact, the only unquestionable evidence of the success in cryopreservation is germination and normal seedling development after thawing.

The embryos stored in LN after immersion in PVS2 solution for 100 minutes at $0{ }^{\circ} \mathrm{C}$ showed less expansion of the hypocotyl-radicle axis and cotyledons than non-stored embryos (control) after 30 days of in vitro growth (Fig. 2D).

Zygotic embryos, such as those used in this study, are complex structures with a heterogeneous cellular composition that may differ in sensitivity to storage (Kulus, 2016). Apparently, the root meristem is more sensitive to damage in relation to the apical meristem. When damage occur directly in these regions, they can inhibit or slow embryo development after storage in LN (Engelmann, 2004), which could explain the slower development of cryopreserved embryos, described here.

After 60 days of in vitro growth, the embryos that had previously developed into normal seedlings, showed a taproot and the formation of the first leaf pairs (Fig. 2E), and they could possibly be acclimatized.

\section{Determination of thawing time}

Regarding thawing time, it was observed that, with the increased time in the water bath at $40^{\circ} \mathrm{C} \pm 2{ }^{\circ} \mathrm{C}$, there was a decrease in the percentage of germination and formation of normal seedlings (Fig. 3).

The percentage of germination and formation of normal seedlings for embryos thawed for 1 minute in a water bath did not differ statistically from embryos that were thawed directly in RS (time 0 ) for 15 minutes at room temperature $\left(25^{\circ} \mathrm{C} \pm\right.$ $\left.2{ }^{\circ} \mathrm{C}\right)$. However, both were statistically different from other periods (3,5 and 10 minutes).

As the temperature rises during thawing, the viscosity of the cryoprotectant solution decreases, therefore, the penetrating components of the PVS2 solution previously used can diffuse. As a consequence of diffusion and prolonged explant exposure to this condition, these components may become toxic (Yi et al., 2012), which could possibly have caused the decrease in the germination percentage of embryos after 3, 5 and 10 minutes. While thawing in RS, PVS2 components also spread, but are readily washed in RS, then being removed along with the RS solution without toxicity to embryos. Thus, since there was no

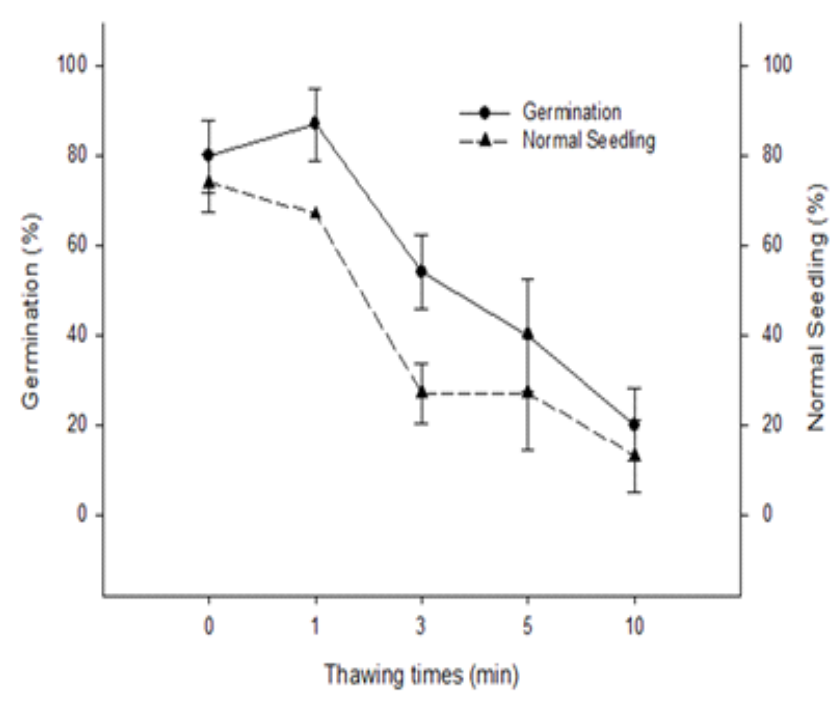

Fig. 3. Percentage of germination and normal seedlings obtained from cryopreserved zygotic embryos subjected to different thawing times ( $0,1,3,5$ and 10 minutes) after 30 days of in vitro growth. The bars represent the mean standard error, according to the Scott-Knott test at 5\% probability 
statistical difference between thawing in RS and 1 minute in a water bath, thawing could be directly performed in RS for 15 minutes at room temperature $\left(25^{\circ} \mathrm{C} \pm 2{ }^{\circ} \mathrm{C}\right)$, as RS decreases the possibility of cell toxicity and eliminates the need for the use of a water bath.
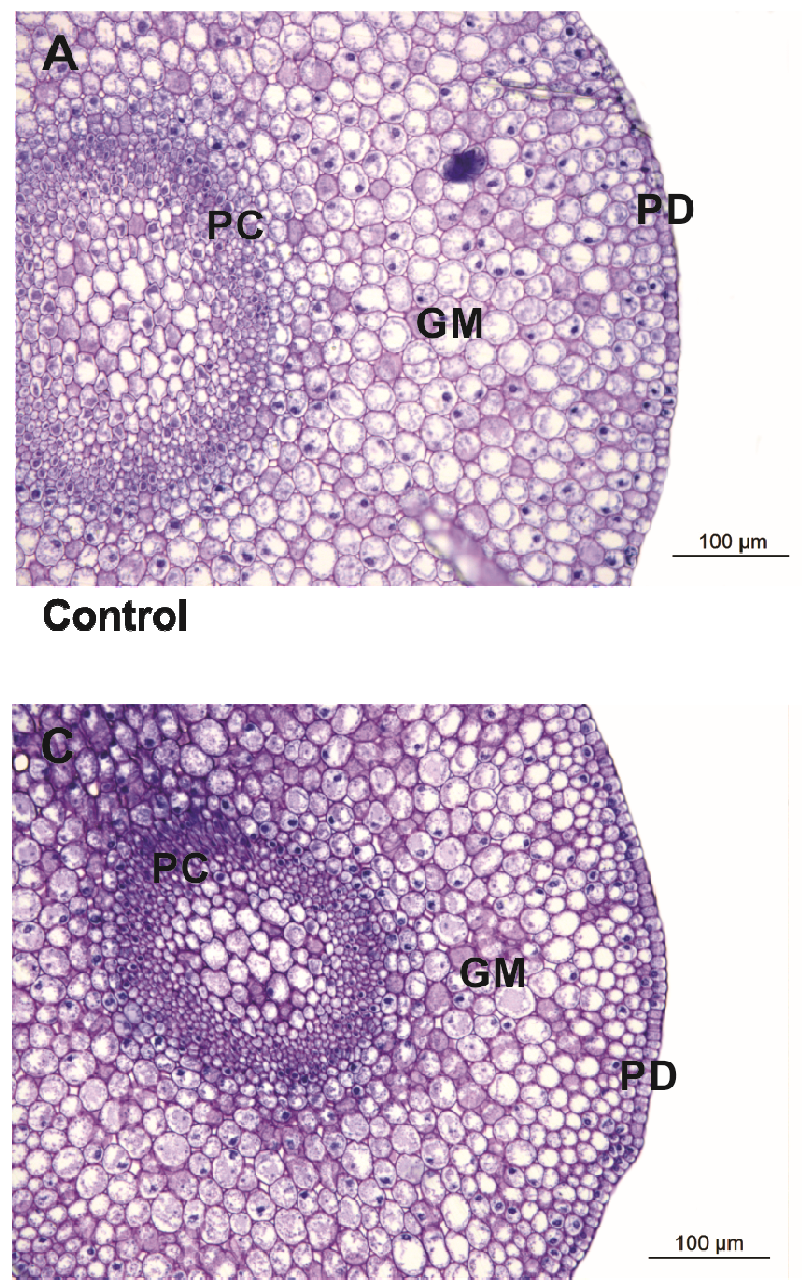

$100 \mathrm{~min}$ PVS2

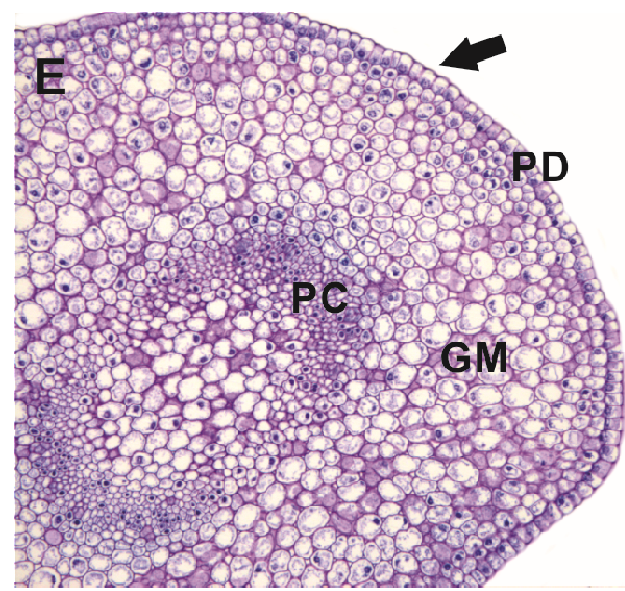

0 min PVS2
Histological analysis

In embryos that were excised and not subjected to vitrification solutions and storage in LN (control), it was observed, from histological sections, that embryo middle cells were turgid, without the presence of large intercellular spaces,
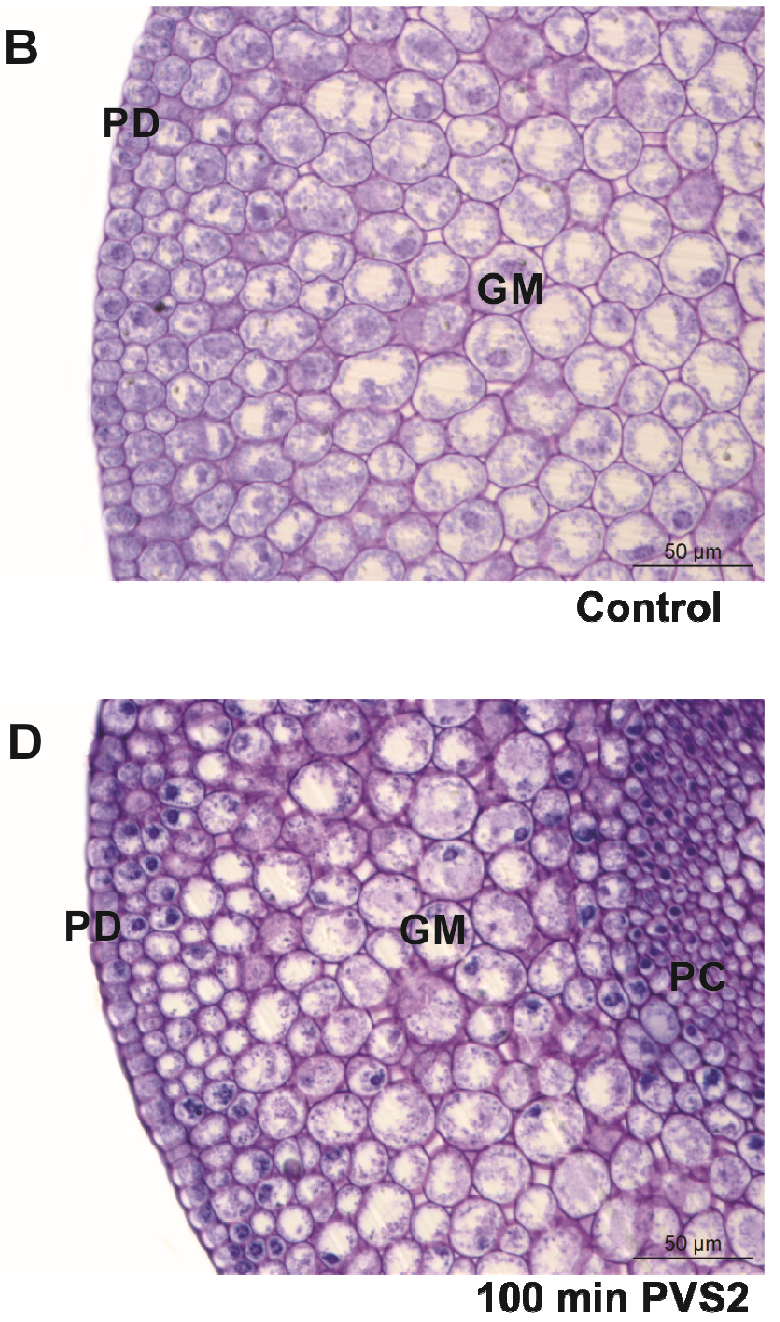

\section{0 min PVS2}

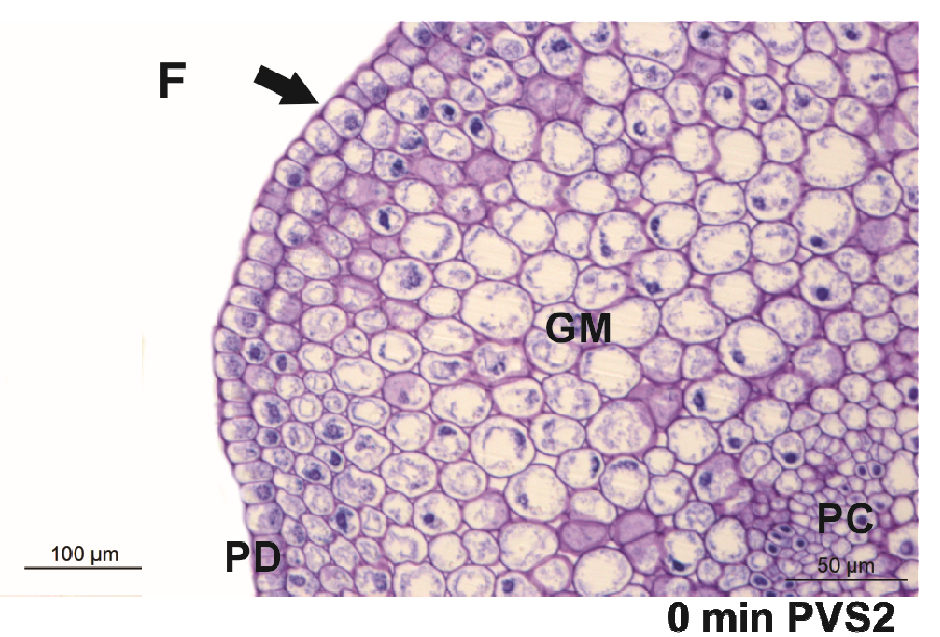

Fig. 4. Histological section of embryos stored in LN with or without the use of PVS2 in relation to that non-stored (control). (A and B) Middle segment of the control (magnification 20x and 40x), (C and D) Embryos middle segment that were previously immersed for $100 \mathrm{~min}$ in PVS2 (magnification 20x and 40x). (E and F) Embryos middle segment with no cryoprotectant (magnification $20 \times$ and $40 \times$ ) demonstrating plasmolysis (arrow). PD - protoderm; GM - ground meristem; PC - procambium 
450

with the protoderm cell content intact (Fig. 4A and B).

Embryos stored in LN that were previously immersed in PVS2 solution for 100 minutes at $0{ }^{\circ} \mathrm{C}$ showed cells caracteristics quite similar to the control; however, in protoderm and ground cells, an increase in number of plasmolyzed cells was observed (Figs. 4C and 4D).

The observed plasmolysis is due to the water efflux by the osmotic action of the cryoprotectant solution used. The joint action of the decreasing water content observed due to the presence of plasmolysis, together with the vitrifying action of PVS2 during the quick immersion in LN, may allow the embryos to be cryopreserved and, after thawing, they can resume their growth in vitro.

Just as observed in this research, in a histological study conducted by Mari $e t$ al., (1995) with cryopreserved coffee apices from species $C$. racemosa Lour. and C. sessiliflora Bridson, it was shown that, after dehydration and storage in $\mathrm{LN}$, meristematic surviving apex cells had a large number of plasmolyzis, with the densest cytoplasm. Yi et al., (2012) also observed plasmolysis in their treatments, which had the highest regeneration value, showing that cell water efflux is necessary, so that storage and subsequent resumption of explant growth can occur.

Since the highest regeneration rates were observed in this treatment, we assume that, when the optimal degree of plasmolysis is achived, this can provide high regeneration values. However, in spite of the cellular water efflux, which is an important factor for the success of the cryopreservation, the excessive efflux can cause cell death.

We observed the excessive water efflux in embryos which were stored in LN without the use of PVS2. In these embryos, a large number of plasmolysis was observed in almost all protoderm cells and also in the ground meristem (Fig. 4E and F). The plasmolysis observed differs from those verified in embryos stored in LN, which were previously immersed in PVS2 for 100 minutes (Fig. 4C and D), due a bigger away from the cell wall. This finding could explain why non-treated embryos did not survive after storage in $\mathrm{LN}$.

Jeon et al. (2015) used chrysanthemum apical buds and observed that, when the apical buds were exposed to LN without immersion in a cryoprotective solution, the apical buds showed visible freezing damage, with irregular cell nucleus, condensed cytoplasm, membrane rupture with leakage of cellular material and the disappearance of the cell wall. We, on the other hand, did not find large cell changes caused by freezing damage, except for plasmolysis.

Starch accumulation has been reported in histological studies as one of the cellular changes observed, for example, in apices of coffee (Mari et al., 1995) and yam (Barraco et al., 2014), and embryogenic massess of gentiana (Mikula et al., 2005). However, unlike these studies, starch accumulation was not observed in any of the evaluated zygotic embryos, regardless of treatment to which they were subjected. The nonvisualization of starch accumulation is possibly due to missing the optional preculture step with a high sucrose concentration. During this step, sucrose, which is a non-penetrating cryoprotectant, is cleaved, and its products enter the cell, where they are converted into starch, and can thus be visualized in histological studies after cryopreservation (Mikula et al., 2005; Sajini et al., 2011).

\section{Conclusions}

The cryopreservation of $C$. arabica $\mathrm{L}$. zygotic embryos is possible by vitrification, through immersion in PVS2 vitrifying solution at $0{ }^{\circ} \mathrm{C}$ for 100 minutes and, subsequently, direct thawing in Recovery Solution.

\section{Acknowledgements}

The authors would like to thank Embrapa and Consórcio Pesquisa Café for providing resources for the implementation of the project (02.13.02.027.00.00) and Coordenadoria de Aperfeiçoamento de Pessoal de Nível Superior (CAPES) for granting the scholarship.

\section{References}

Araujo RF, Araujo EF, Cecon PR, Sofia TTIV (2008). Conservação de sementes de café (Coffea arabica $L$.) despolpado e não despolpado. [Conservation of coffee seeds (Coffea arabica L.) pulped and nonpulped]. Revista Brasileira de Sementes 30:71-78.

Barraco G, Sylvestre I, Collin M, Escout J, Lartaud M, Verdeil JL, Engelmann F (2014). Histocytological analysis of yam (Dioscorea alata) shoot tips cryopreserved by encapsulation-dehydration. Protoplasma251:177-189.

Bojórquez-Quintal JEA, Sánchez-Cach LA, Gamboa-Tec NF, QuintalTun F, Minero-García Y, Martínez-Estévez M, ... Santos-Briones C (2011). Effect of plant growth regulators on in vitro germination of coffee zygotic embryos. African Journal of Biotechnology 10:1905619065.

Clemente ADCS, Carvalho MLM, Guimarães RM (2012). Suitability of the tetrazolium test methodology for recently harvested and stored coffee seeds. Ciência e Agrotecnologia 36:415-423.

CONAB - Companhia Nacional de Abastecimento: Primeiro levantamento safra 2016. Retrieved: 2016 May 13 from: http://www.conab.gov.br/OlalaCMS/uploads/arquivos/16_01_2 0_17_01_56_boletim_cafe_-janeiro_2016.pdf.

Dela Cruz G, Estrada S, Orozco S, Labrada PM (1992). Methodology to micropropagate and biochemical identification of coffee plants varieties. 1 ed. Publicaciones Instituto Jorge Domitrov, Cuba.

Dulloo ME, Ebert AW, Dussert S, Gotor E, Astorga C, Vasquez N, ... Snook L (2009). Cost Efficiency of cryopreservation as a long-term conservation method for coffee genetic resources. Crop Science 49:2123-2138.

Dussert S, Chabrillange N, Engelmann F, Anthony F, Hamon S (1997). Cryopreservation of coffee (Coffea arabica L.) seeds: importance of the precooling temperature. CryoLetters 18:269276.

Dussert S, Chabrillange N, Engelmann F, Anthony F, Louarn J, Hamon S (1998). Cryopreservation of seeds of four coffee species (Coffea arabica, C. costatifructa, C. racemosa and C. sessiliflora): importance of water content and cooling rate. Seed Science Research 8:9-15.

Dussert S, Engelmann F (2006). New determinants for tolerance of coffee (Coffea arabica L.) seeds to liquid nitrogen exposure. CryoLetters 27:169-178. 
Engelmann F (2004). Plant cryopreservation: Progress and prospects. In Vitro Cellular \& Developmental Biology - Plant 40:427-433.

Ferreira DF (2014). Sisvar: A guide for its bootstrap procedures in multiple comparisons. Ciência e Agrotecnologia 38:109-112.

Jeon SM, Arun M, Lee S-Y, Kim CK (2015). Application of encapsulation-vitrification in combination with air dehydration enhances cryotolerance of Chrysanthernum morifolium shoots tips. Scientia Horticulturae 194:91-99.

Kim HH, Lee YG, Shin DJ, Ko HC, GwagJG, Cho EG, Engelmann F (2009). Development of alternative plant vitrification solutions in droplet-vitrification procedures. CryoLetters 30:320-334.

Kulus D, Zalewska M (2014). Cryopreservation as a tool used in longterm storage of ornamental species - a review. Scientia Horticulturae 168:88-107.

Kulus D (2016). Application of cryogenic technologies and somatic embryogenesis in the storage and protection of valuable genetic resources of ornamental plants. In: Somatic embryogenesis in ornamentals and its applications. Mujib A (Ed), Springer India pp 1-27.

Lambardi M, Fabbri A, Caccavale A (2000). Cryopreservation of white poplar (Populus alba L.) by vitrification of in vitro-grown shoot tips. Plant Cell Reports 19:213-218.

Mari S, Engelmann F, Chabrillange N, Huet C, Michaux-Ferrière N (1995). Histo-cytological study of coffee (Coffea racemosa and $C$. sessiliflora) apices of in vitro plantlets during their cryopreservation using the encapsulation-dehydration technique. CryoLetters 16:289-298.

Matsumoto T, Sakai A, Yamada K (1994). Cryopreservation of in vitrogrown apical meristems of wasabi (Wasabia japonica) by vitrification and subsequent high plant regeneration. Plant Cell Reports 13:442-446.

Mikula A, Tykarska T, Kuraś M (2005). Ultrastructure of Gentiana tibetica proembryogenic cells before and after cooling treatments. CryoLetters 26:367-378.

Nass LL, Nishikawa MAN, Fávero AP, Lopes MA (2008). Prémelhoramento de germoplasma vegetal. In: NASS LL (Org). Recursos genéticos vegetais. Brasília: Embrapa Recursos genéticos e Biotecnologia pp 683-716.

Pinto MS, Paiva R, Silva DPC, Santos PAA, Freitas RT, Silva LC (2016). Cryopreservation of coffee zygotic embryos: dehydration and osmotic rehydration. Ciência e Agrotecnologia 40(4):380-389.
Sajini KK, Karun A, Amarnath CH, Engelmann F (2011). Cryopreservation of coconut (Cocos nucifera $\mathrm{L}$.) zygotic embryos by vitrification. CryoLetters 32:317-328.

Sakai A, Engelmann F (2007). Vitrification, encapsulation-vitrification and droplet-vitrification: A review. CryoLetters 28:151-172.

Sakai A, Kobayashi S, Oiyama I (1990). Cryopreservation of nucellar cells of navel orange (Citrus sinensis Osb. var. brasiliensis Tanaka) by vitrification. Plant Cell Reports 9:30-33.

Santana-Buzzy N, Rojas-Herrera R, Galaz-Ávalos RM, Ku-Cauich JR, Mijangos-Cortés J, Gutiérrez-Pacheco LC, ... Loyola-Vargas VM (2007). Advances in coffee tissue culture and its practical applications. In Vitro Cellular \& Developmental Biology - Plant 43:507-520.

Silva SA, Queiroz DM, Ferreira WPM, Corrêa PC, Rufino JLS (2016). Mapping the potential beverage quality of coffee produced in the Zona da Mata, Minas Gerais, Brazil. Journal of the Science of Food and Agriculture 96(9):3098-3108.

Simoes-Costa MC, Carapuca E, Moura IR (2009). Somatic embryogenesis induction in different genotypes of Coffea spp. Acta Horticulturae 812:295-300.

Sridharan G, Shankar AA (2012). Toluidine blue: A review of its chemistry and clinical utility. Journal of Oral and Maxillofacial Pathology 16:251-255.

Tao D, Li PH (1986). Classification of plant cell cryoprotectants. Journal of Theoretical Biology 123:305-310.

Valdés YC (2012). Conservación de recursos fitogenéticos de cafeto (Coffea spp.) por métodos biotecnológicos: una alternativa para su preservación. [Conservation of plant genetic resources of coffee (Coffea spp.) by biotechnological methods: an alternative for preservation] Cultivos Tropicales 33:29-39.

Verleysen H, Samyn G, Bockstaele E, Van Debergh P (2004). Evaluation of Analytical Techniques to Predict Viability after Cryopreservation. Plant Cell, Tissue and Organ Culture, 77(1):1121.

Volk GM, Walters C (2006). Plant vitrification solution 2 lowers water content and alters freezing behavior in shoot tips during cryoprotection. Cryobiology 52:48-61.

YiJY, Sylvestre I, Colin M, Salma M, Lee SY, Kim HH, ... Engelmann F (2012). Improved cryopreservation using droplet-vitrification and histological changes associated with cryopreservation of Madder (Rubia akane Nakai). Korean Journal of Horticultural Science and Technology 30:79-84. 